Supporting Information

\title{
Representing the Methane Oxidation Reaction via Linking First Principles Calculations and Experiment with Graph Theory
}

\author{
Lauren Takahashi ${ }^{* \dagger}$, Junya Ohyama ${ }^{\S}$, Shun Nishimura ${ }^{\ddagger}$, Keisuke Takahashi ${ }^{\dagger}$ \\ †Department of Chemistry, Hokkaido University, North 10, West 8, Sapporo 060-8510, Japan \\ $\ddagger$ Faculty of Advanced Science and Technology, Kumamoto University, 2-39-1 Kurokami, Chuo-ku, \\ 8 Kumamoto, 860-8555, Japan \\ §Graduate School of Advanced Science and Technology, Japan Advanced Institute of Science and \\ Technology, 1-1 Asahidai, Nomi,Ishikawa 923-1292, Japan
}

*Corresponding Author:

E-mail: lauren.takahashi@sci.hokudai.ac.jp 


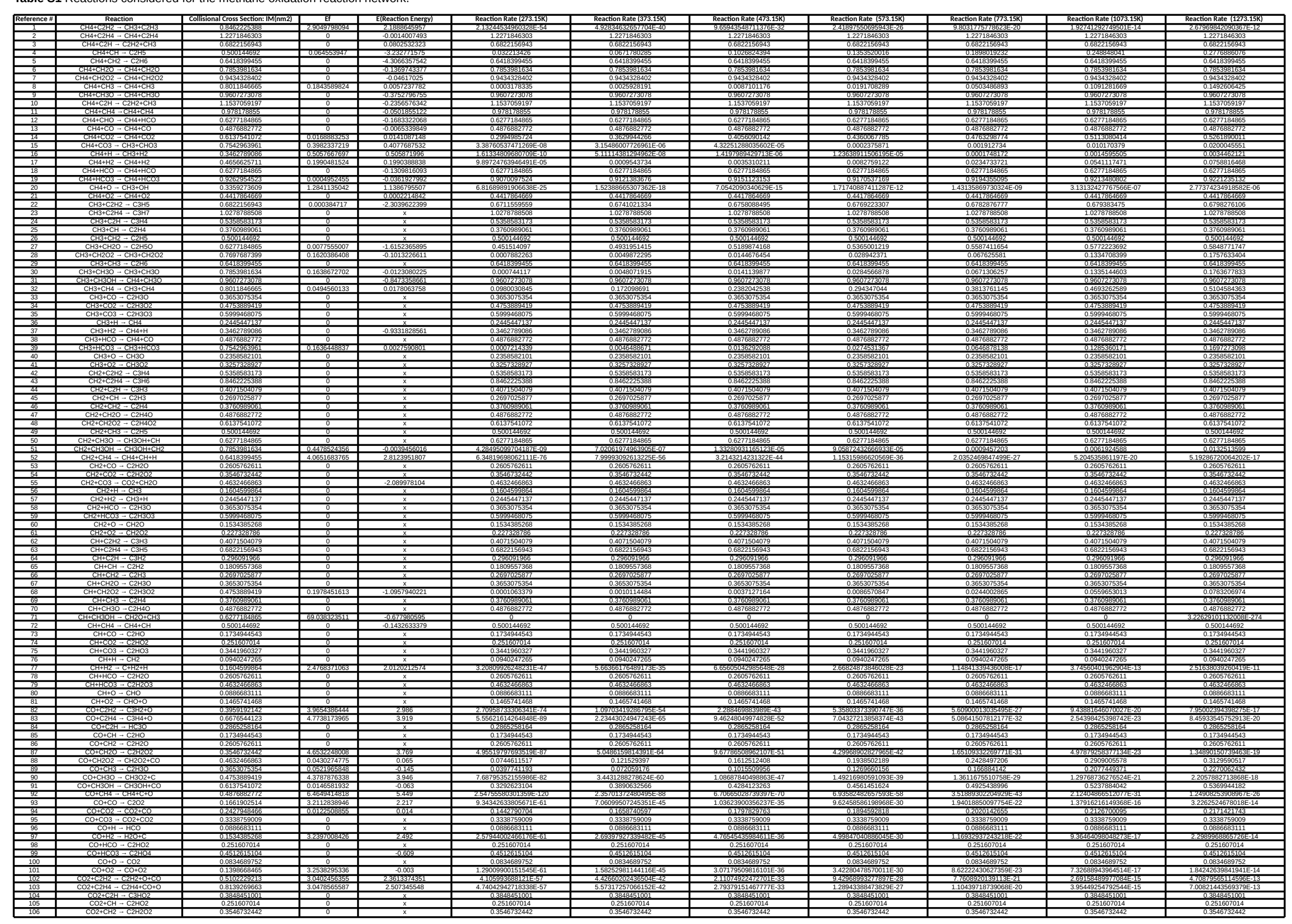




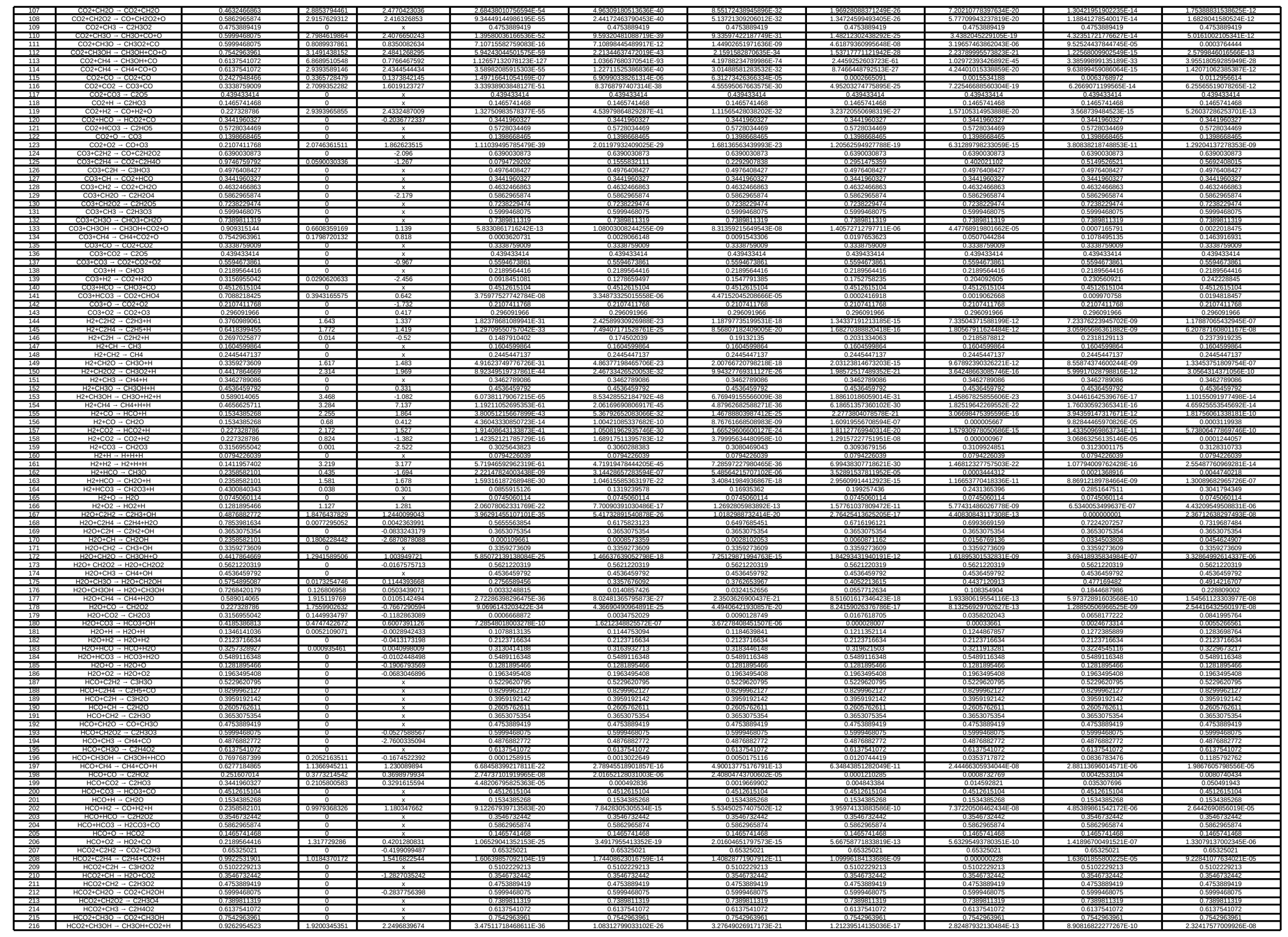




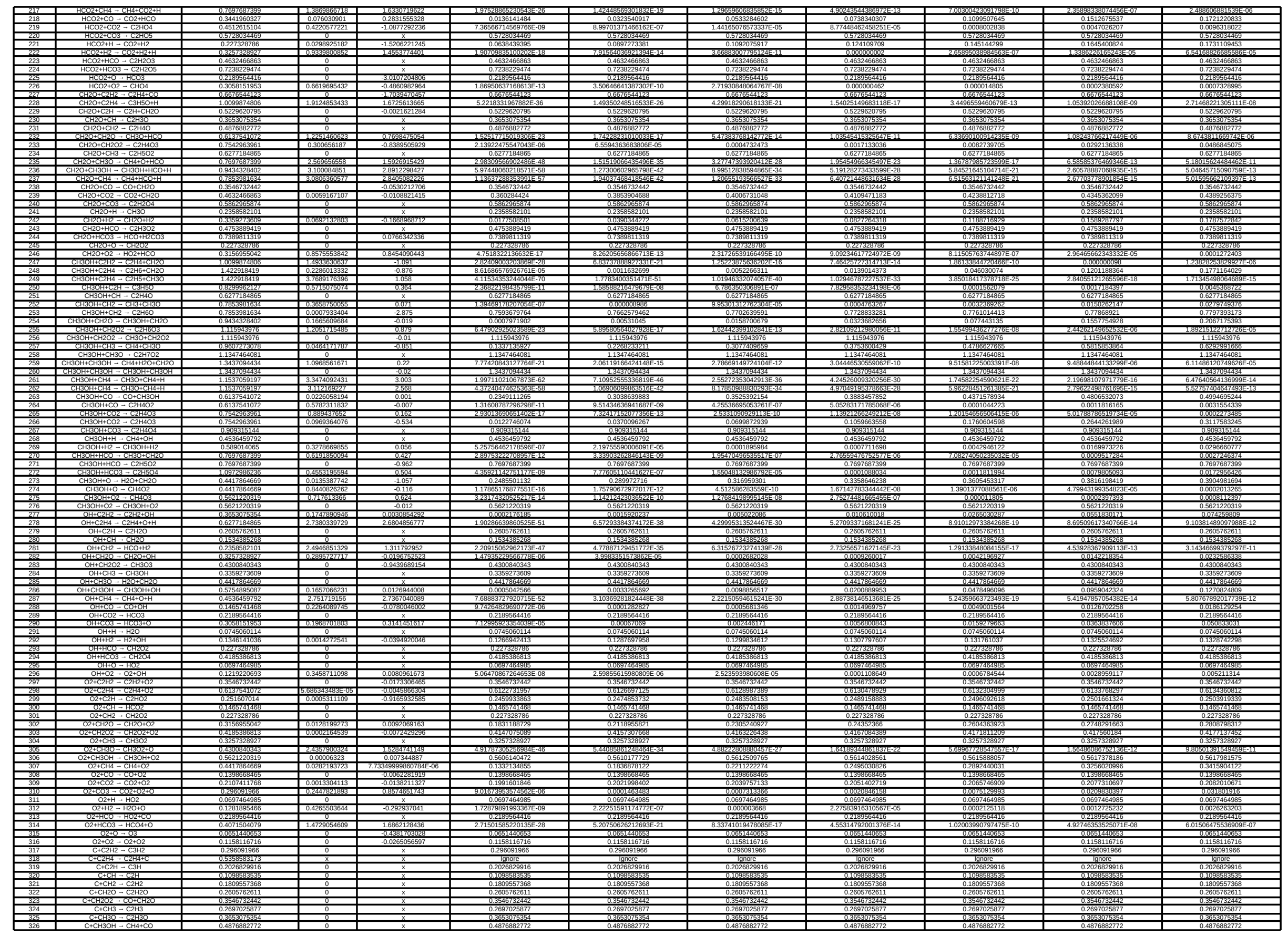




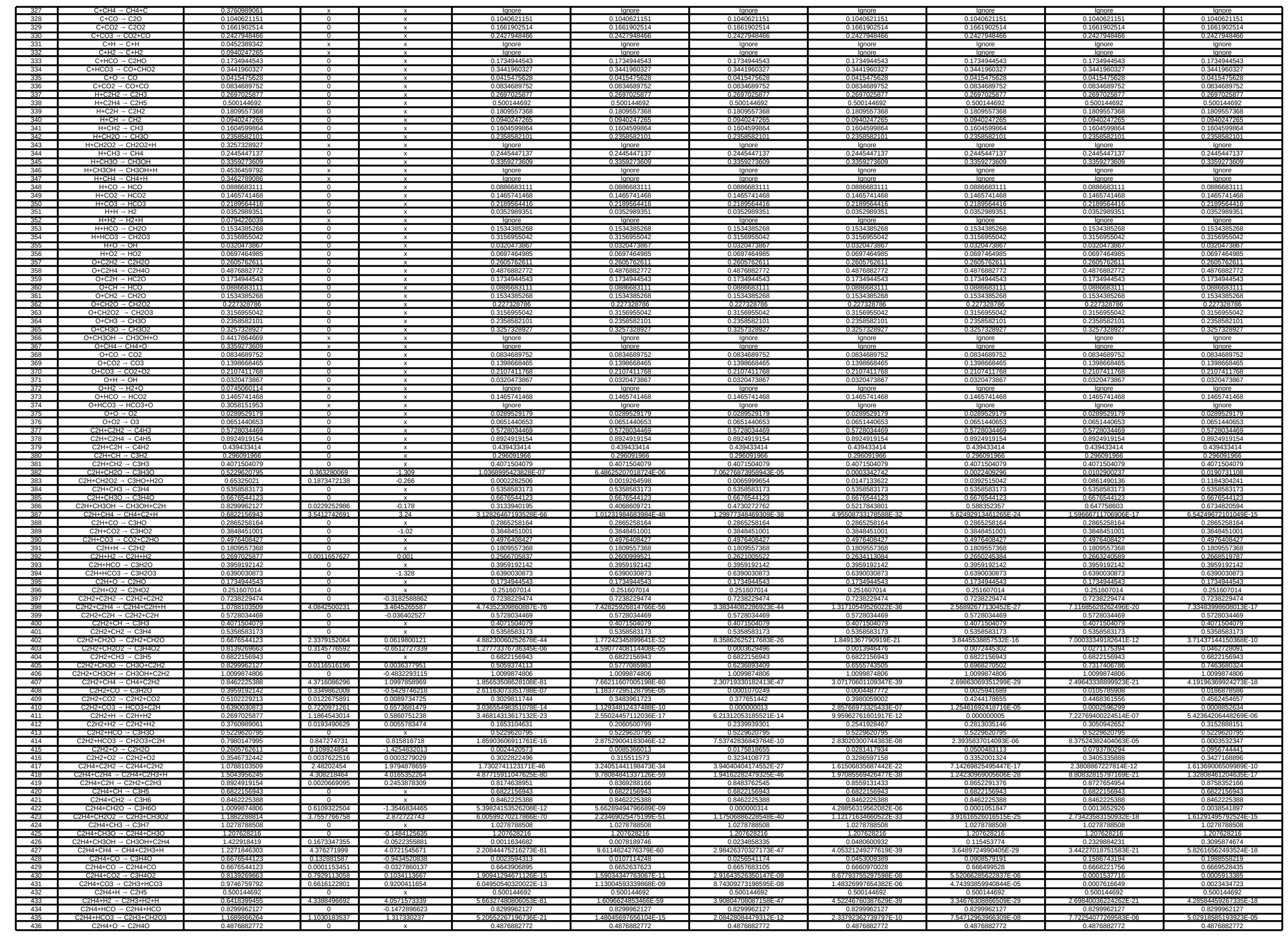




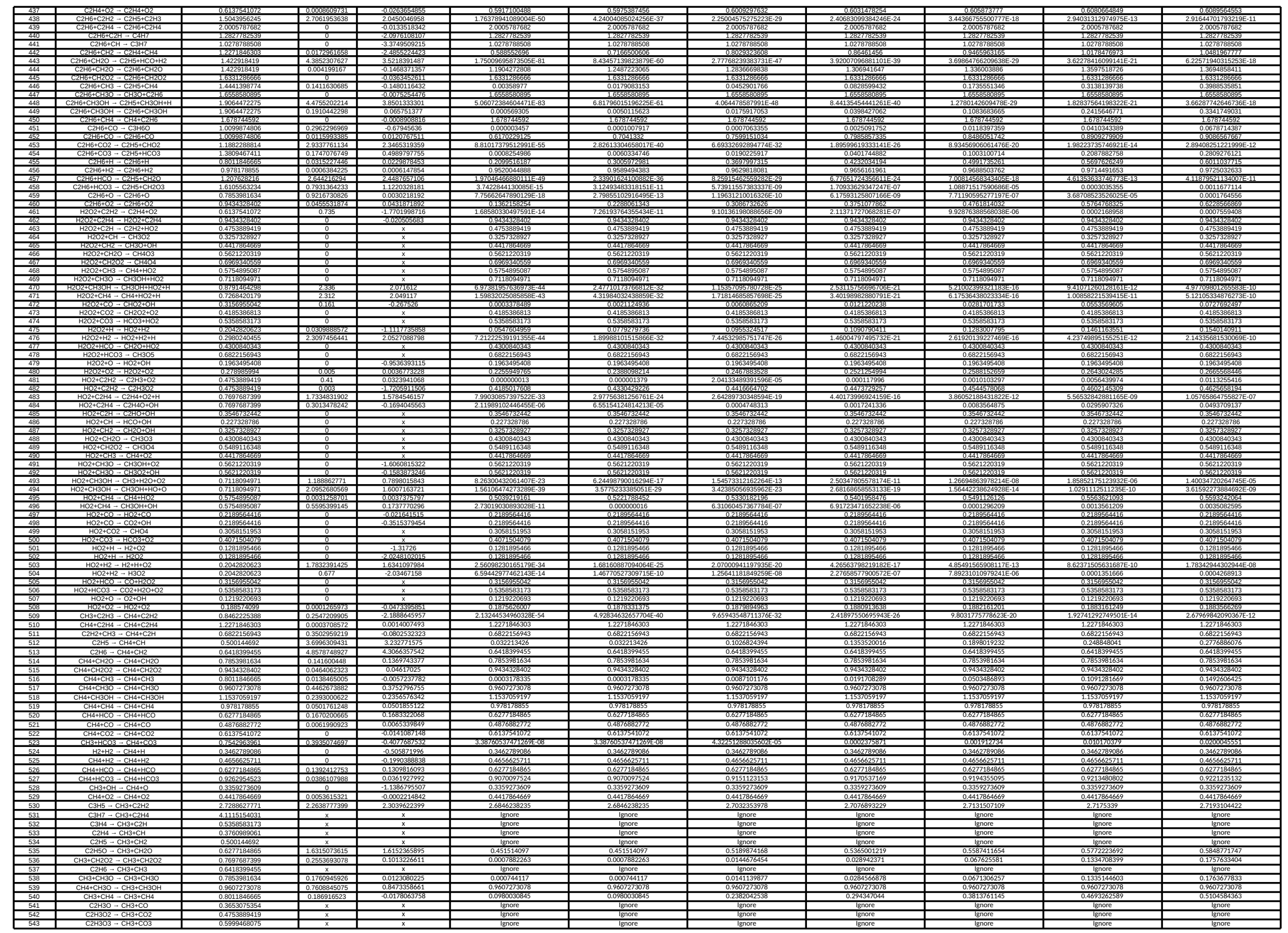




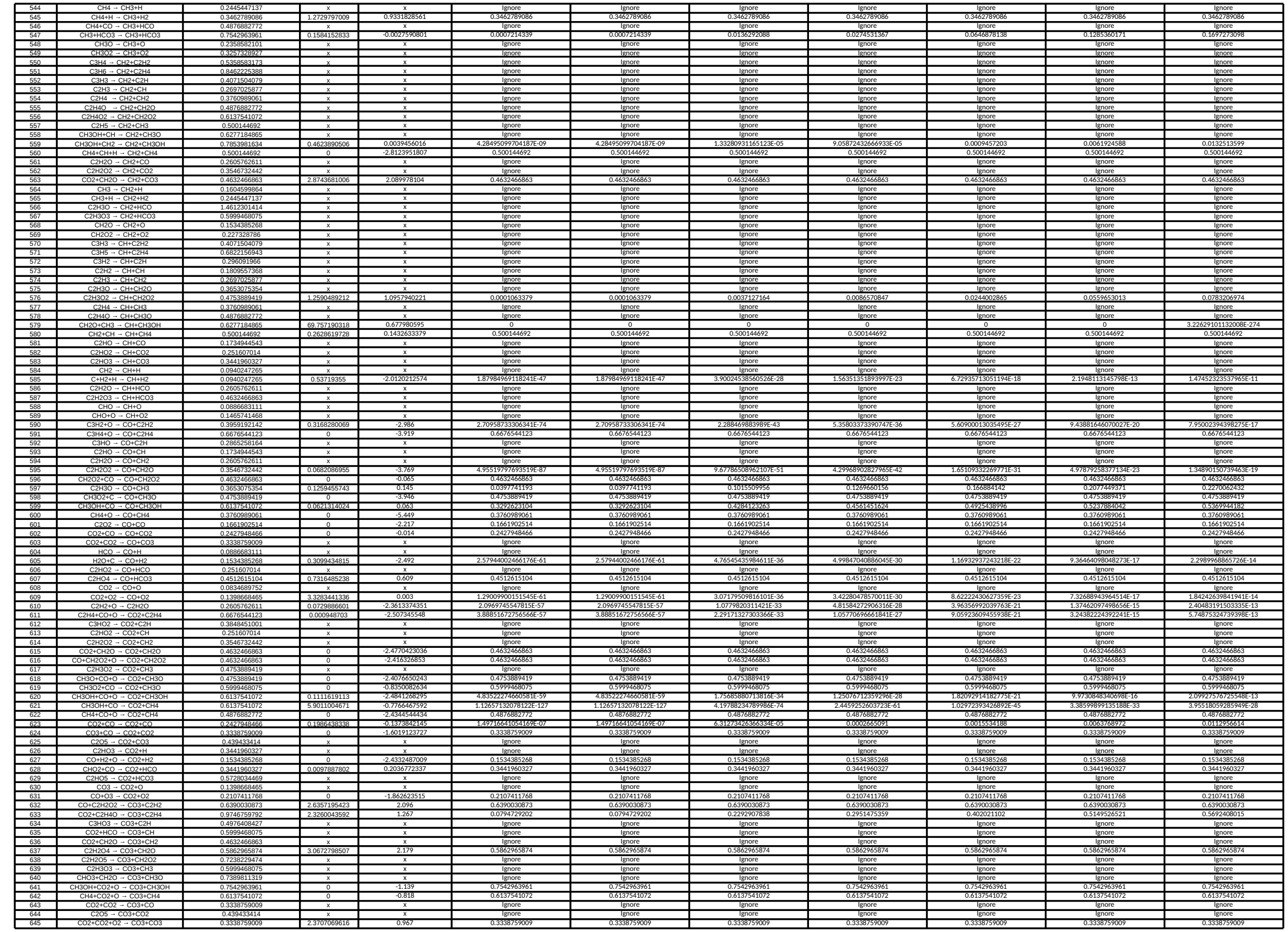




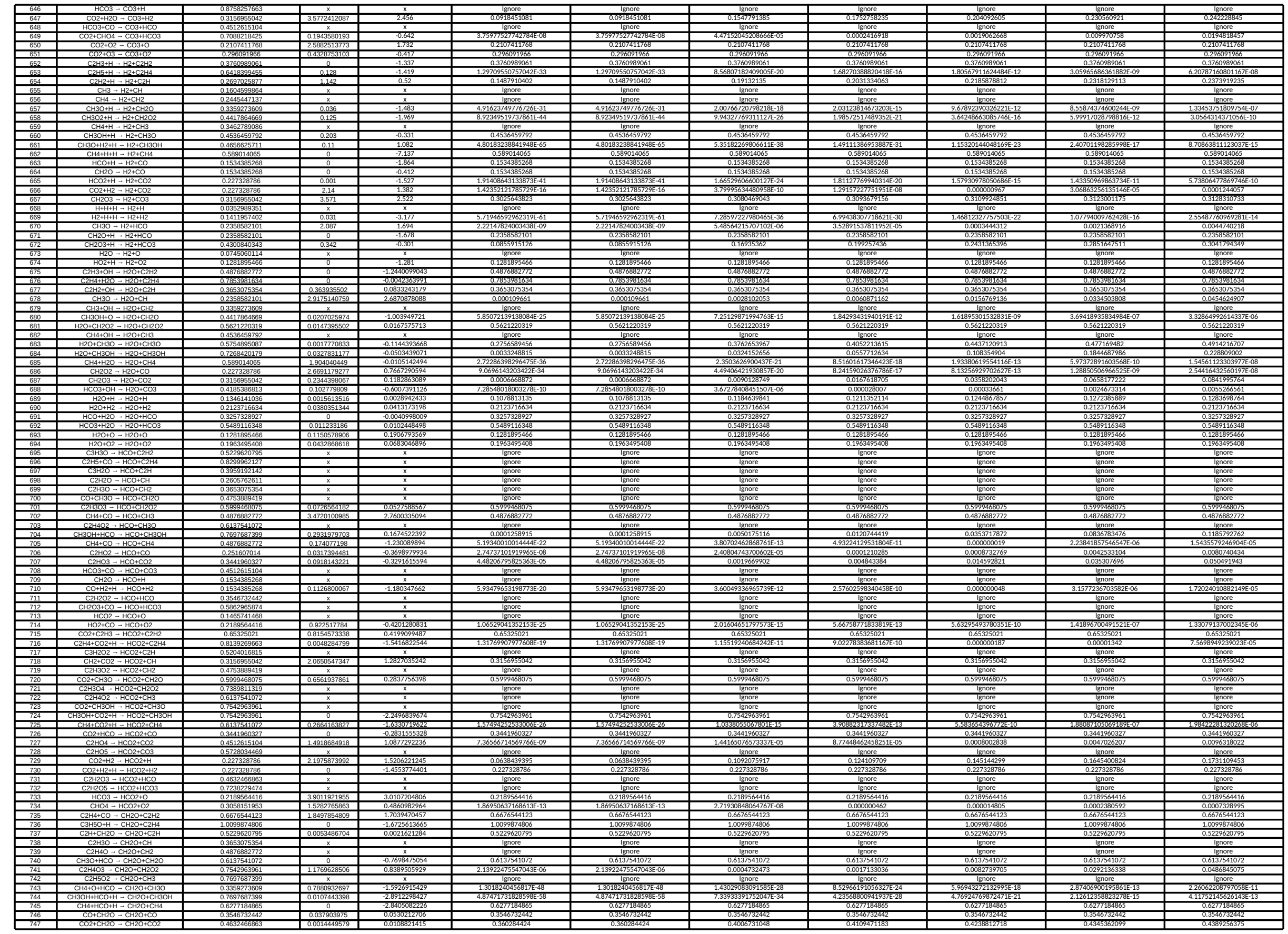




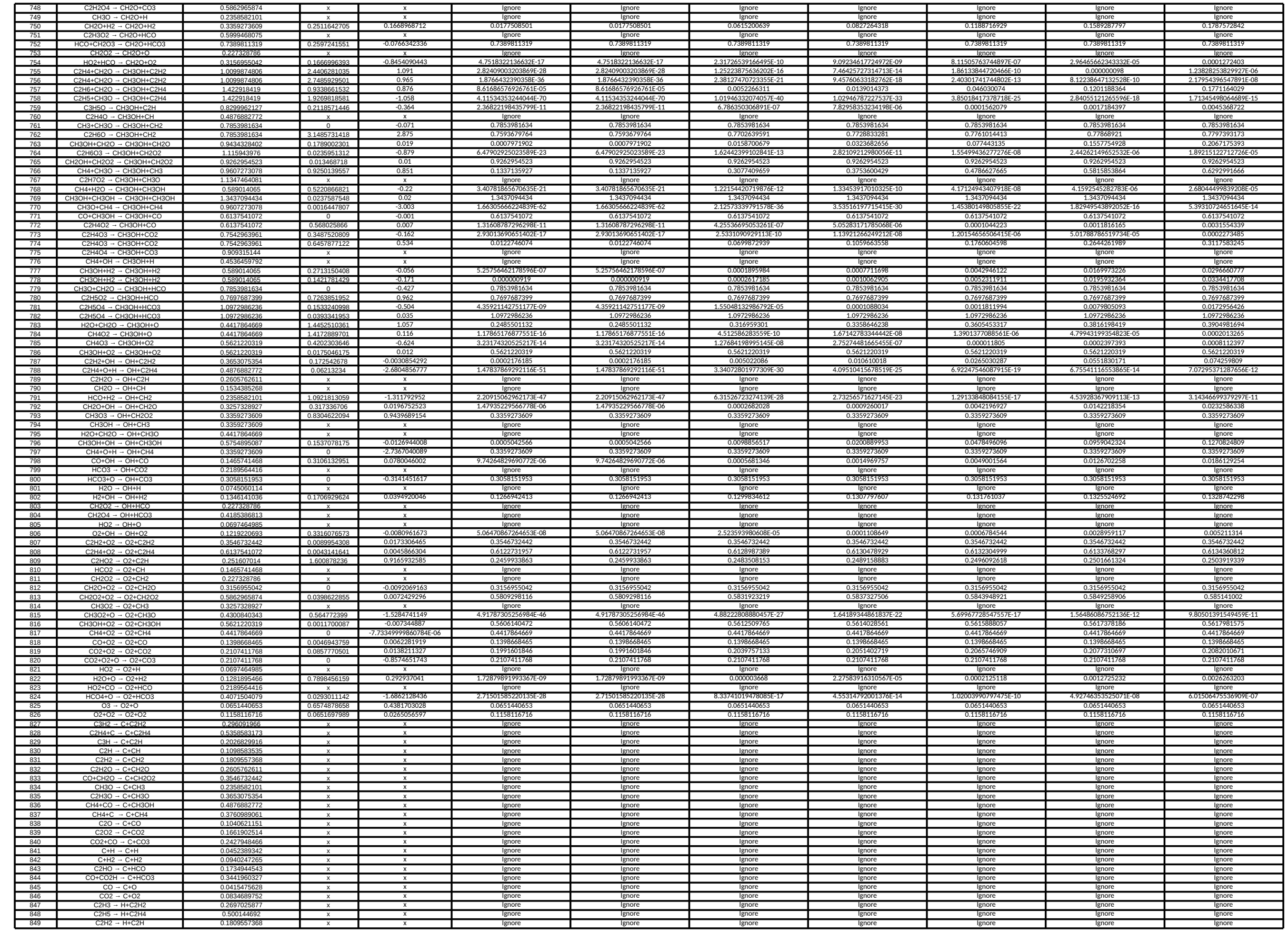




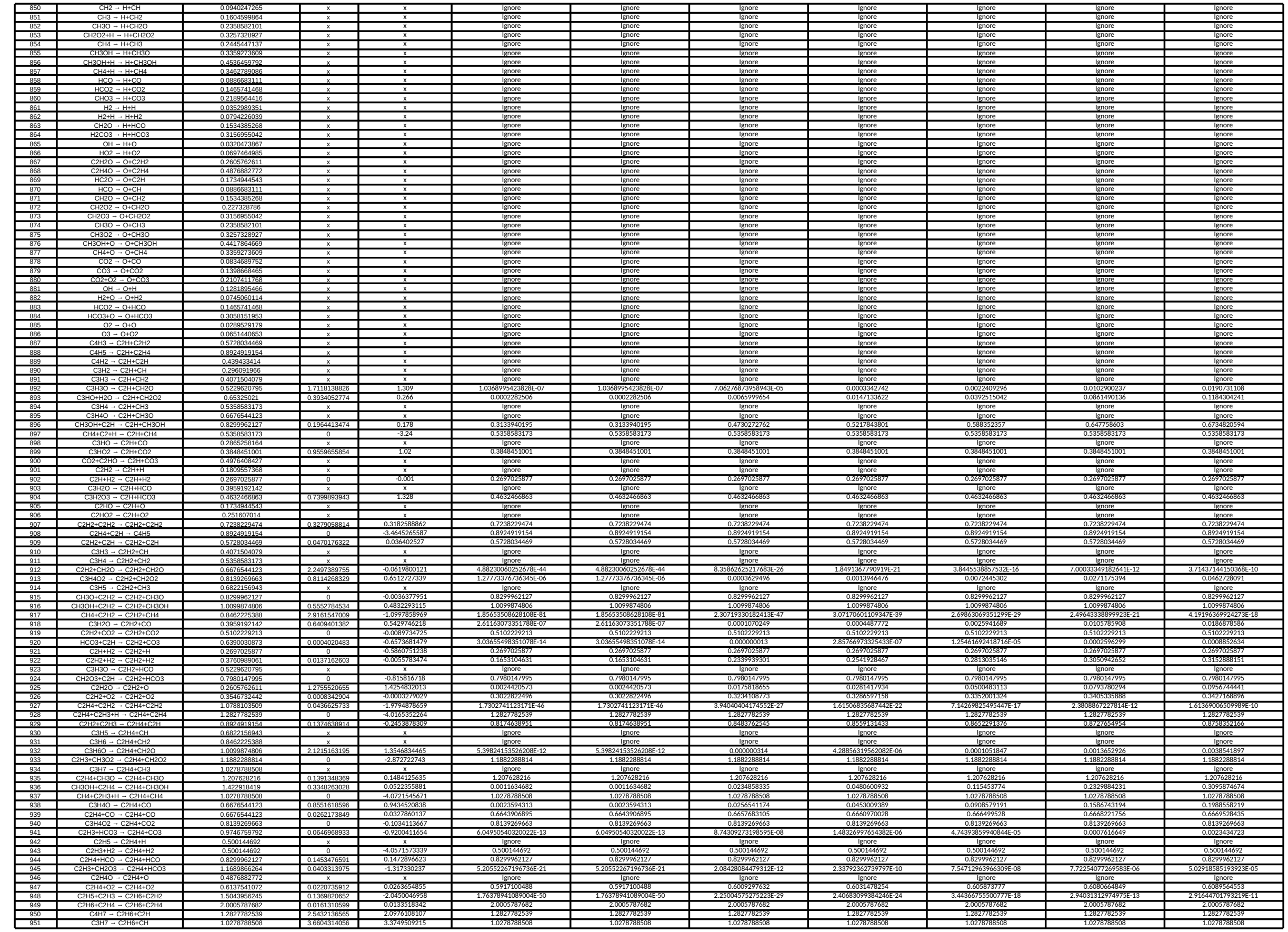




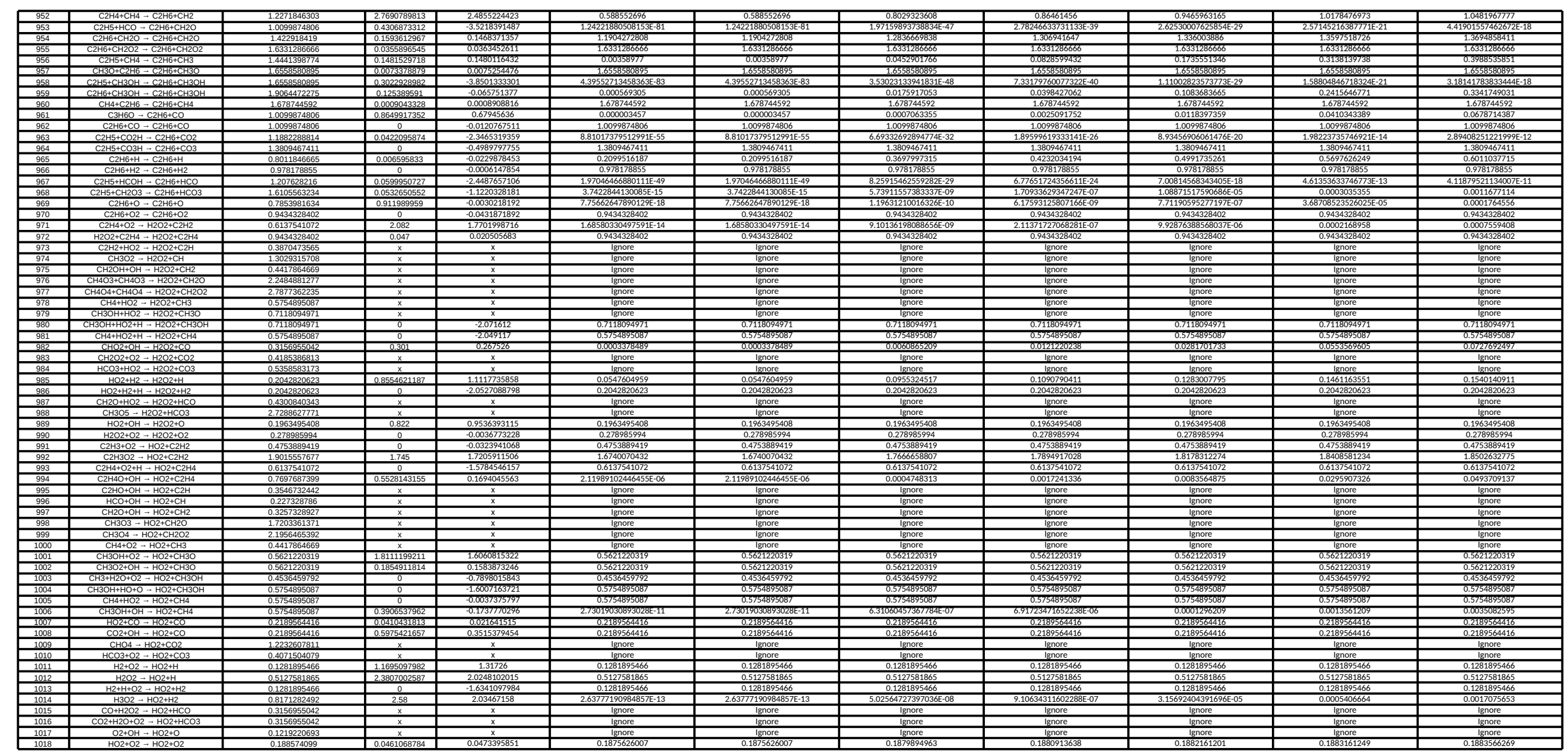


Table S2 Temperature, number of reactions, average edge weight, highest edge weights, and experimental selectivity of $\mathrm{H} 2, \mathrm{CO}, \mathrm{CO} 2, \mathrm{C} 2 \mathrm{H} 4$, and $\mathrm{C} 2 \mathrm{H} 6$.

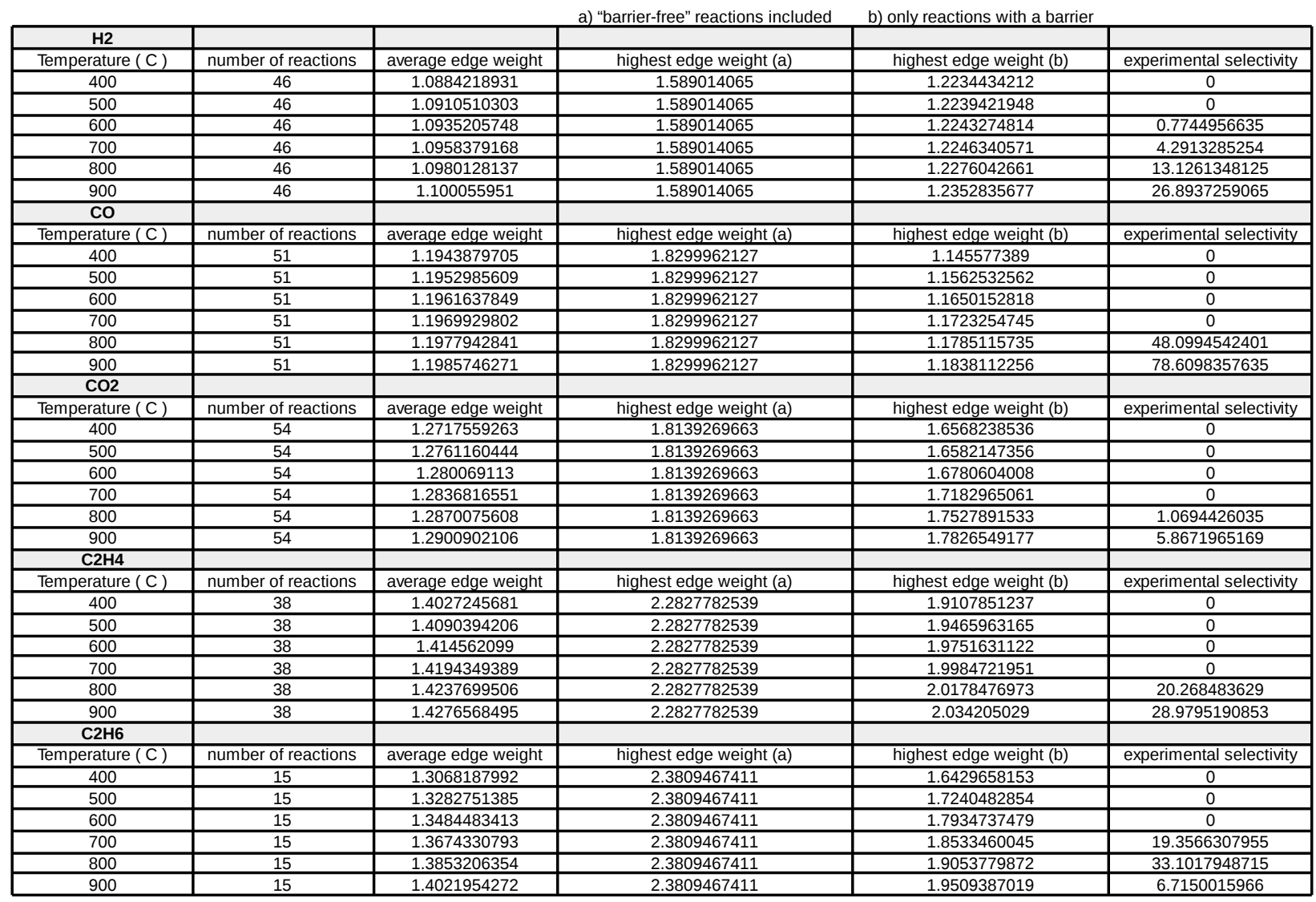

